\title{
Tércio Miranda: uma liderança anarquista na Amazônia (1913-1914)
}

\section{Luciano Everton Costa Teles*}

Resumo: O texto em tela tem como finalidade recuperar a trajetória de um personagem, Tércio Miranda, que atuou de forma significativa na organização dos trabalhadores no Amazonas, promovendo a fundação de sindicatos, em particular dos trabalhadores gráficos e se envolvendo na produção de um jornal intitulado $A$ Lucta Social, pelo qual buscou, além de difundir os ideais anarquistas, conscientizar e organizar os trabalhadores da região. Com efeito, procurou-se responder uma questão central: de que forma a trajetória de Tércio Miranda, em especial suas "expressões individuais", possibilitam iluminar aspectos de um contexto histórico geral?

Palavras-chave: história operária; trajetória anarquista; Tércio Miranda.

Abstract: The text on screen is intended to recover the trajectory of a character, Tércio Miranda, who acted significantly in the organization of workers in the Amazon, promoting the establishment of trade unions, in particular the graphics workers, and getting involved in the production of a newspaper titled the Social Lucta, by which sought, and spread the ideals anarchists, educate and organize workers in the region. In fact, he tried to answer one central question: how the trajectory of Tércio Miranda, especially their "individual expression", enable illuminate aspects of a general historical context?

Keywords: workers history; trajectory anarchist; Tércio Miranda.

\section{Considerações iniciais}

\footnotetext{
"Aparece brevemente este jornal, que se destina ao operariado. A sua publicação será eventual, e a sua ação será educativa, indicando aos que trabalham, o Futuro, que a emancipação nos trará, feliz e armonioso". ' Com essas palavras o jornal A Lucta Social se apresentou aos trabalhadores amazonenses. Originando-se no ano de 1914, tornouse instrumento, do grupo que o produziu, de intervenção no mundo do trabalho, buscando conscientizar, organizar e mobilizar os trabalhadores numa perspectiva libertária que vislumbrava, dentre outras coisas, um futuro de justiça social.

* Doutorando em História pela Universidade Federal do Rio Grande do Sul - PPGH. Mestre em História Social pela Universidade Federal do Amazonas. Professor Assistente 2 da Universidade do Estado do Amazonas. Bolsista (RH-Interiorização - DRA) da Fundação de Amparo à Pesquisa do Estado do Amazonas - FAPEAM. E-mail: lucianoeverton777@hotmail.com

1 A Lucta Social (Suplemento ao n. 1). Manaus, 27 jun. 1914, p. 1.
} 
Mas quem era o editor do jornal? Que grupo gravitava em seu entorno? Quais eram as suas características? Que elementos contribuíram para sua emergência? Como se deu a presença e inserção do anarquismo na Amazônia e as disputas com outras correntes políticas? Estas perguntas surgiram das discussões realizadas no âmbito da disciplina Análise Bibliográfica I, da linha de pesquisa de relações sociais de dominação e resistência, do Programa de Pós-graduação em História da Universidade Federal do Rio Grande do Sul e, nesse sentido, buscou-se respondêlas. Porém elas são desdobramentos do problema central: de que forma a trajetória de Tércio Miranda, em especial suas "expressões individuais", possibilitam iluminar aspectos de um contexto histórico geral?

\section{Por trás do jornal A Lucta Social: Tércio Miranda}

Nos anos iniciais do século XX, na esteira do avanço do periodismo no Amazonas, impulsionado pela expansão da economia da borracha que promoveu dentre outras coisas as condições técnicas, profissionais e sociais para a emergência dos impressos, surgiu uma variedade de títulos de jornais (diários, pasquins, satíricos...) que buscavam registrar e retratar os acontecimentos sociais. Compondo esse conjunto, se tem a imprensa operária.

Os jornais operários que circularam no Amazonas formavam algo em torno de 14 títulos que se ligavam a diferentes categorias e associações e possuíam perspectivas político-ideológicas variadas, indo do reformismo e do colaboracionismo (como é o caso respectivamente, por exemplo, dos jornais Vida Operária e Tribuna do (aixeiro) ao anarquismo. Desse universo da imprensa operária recortou-se o jornal A Lucta Social² para, por intermédio dele, recuperar a trajetória de Tércio Miranda, este que veio a ser uma das principais lideranças anarquistas na Amazônia, incomodando, em grande medida, com a sua presença e ação, setores da elite local, em especial as autoridades públicas, os diretores das empresas concessionárias dos serviços públicos urbanos e os comerciantes.

Em Portugal, na cidade do Porto, Tércio Miranda viveu e entrou em contato com o anarquismo. Não se sabe exatamente quando e como, porém existem informações que permitem iluminar alguns aspectos desse contato, em especial entre os anos de 1908 e 1912.

Muito embora o movimento libertário em Portugal remonte ao final do século XIX, mais precisamente aos anos de 1886/88 - com a publicação do periódico A Revolução Social - Orgão Comunista e Anarchista ligado à "Associação dos Trabalhadores e Partido Operário do Porto" - foi em 1910 que se publicou o impresso Aurora, agregando militantes anarquistas. O surgimento desse periódico foi tão significativo que gerou, a posteriori, a fundação de uma organização com o objetivo de lhe dar suporte, pois era considerado instrumento de ligação e apoio junto ao trabalhador português, assim como aos trabalhadores do mundo, buscando inclusive apoiar movimentos contestatórios numa perspectiva internacionalista. ${ }^{3}$

2 Cabe destacar que o jornal A Lucta Social teve três fases. A primeira em 1914, com Tércio Miranda. Dessa fase tem-se seis números. Da segunda fase, em 1924, existe apenas um número. Da mesma forma em 1932, terceira fase do jornal. Optou-se por trabalhar a fase de Tércio Miranda, procurando recuperar sua trajetória.

3 CRUZ, Manuel Carvalho Ferreira da. "O Movimento Libertário Portuense à luz do periódico A Aurora (19101919)". (Dissertação de mestrado em História, Universidade do Porto, 2012), p. 27-28. 
Desse processo, em 4 de setembro de 1910, nasceu o "Grupo Aurora Social" do qual Tércio Miranda fez parte, assim como, provavelmente, também participou da "União Geral dos Trabalhadores da Região do Norte", organização que se materializou por volta de 1912 e se tornou pouco tempo depois em Federação Sindicalista. ${ }^{4} \mathrm{O}$ que acabou reforçando essa provável presença de Tércio Miranda na União foi a menção feita pelo periódico A Aurora sobre a sua participação como liderança na Liga D'Educação Nova, em 1912.5

Mas o que fez Tércio se deslocar de Portugal para o Brasil, desenvolvendo suas ações libertárias na Amazônia? Sabe-se que, em 1910, foi implantada a República em Portugal. Tal processo envolveu vários setores, com a participação dos trabalhadores e de suas lideranças, que, ao lado dos republicanos, lutaram para derrubar a monarquia. Sobre essa questão, Pereira salientou que,

\begin{abstract}
em contexto nacional, os republicanos na oposição souberam colorir o seu programa de socialismo, prometendo de uma só vez resolver a questão política e social. Muitos trabalhadores esperaram que o seu discurso fosse sincero, os mais radicais preferiram testar as suas próprias forças. O operariado dividiu-se entre as promessas republicanas e as conquistas efetivas da CGT francesa. ${ }^{6}$
\end{abstract}

Entre os mais radicais, incluindo aí o movimento libertário, a CGT francesa foi uma referência, fonte de energia para essas lideranças que se inspiraram nela e trocaram experiências, seja por correspondências, visitas ou participação em congressos.? Porém, a República assumiu uma forma estritamente burguesa, protelando a participação e os projetos sociopolíticos dos trabalhadores. Nessa esteira, o projeto anarquista, que buscava com sua ação romper com os limites impostos por um regime representativo e excludente, viu-se numa situação complicada.

Nesse quadro, esse movimento se intensificou, produzindo ações e gerando respostas dos governantes republicanos que acabaram "manifestando a sua profunda hostilidade ao movimento autônomo dos trabalhadores". Assim, em 1912, com apoio dos militares e ancorados no militarismo, os governantes realizaram uma verdadeira "caça às bruxas", proibindo a propaganda libertária, perseguindo e prendendo seus líderes. ${ }^{8}$

Talvez Tércio Miranda, como liderança libertária atuando ativamente e pedagogicamente na propaganda e na organização dos trabalhadores do norte de Portugal, percebendo esse momento de tensão social, com perseguições e prisões, tenha resolvido sair de lá.

Além disso, não se deve esquecer que nesse período essa região enfrentava alguns problemas estruturais que podiam também somar e/ou agravar a situação, provocando o deslocamento de portugueses para outras áreas ou países. Entre eles, podem-se destacar as "altas taxas de fecundidade, predomínio de um sistema de pequena propriedade, heranças com partilhas estritas e redes de relações sociais

4 CRUZ. "O Movimento Libertário Portuense à luz do periódico Aurora", p. 32.

5 Inclusive dando o endereço da Liga (Rua das Fontainhas, n. 9, Porta do Sol), o que é uma evidência forte da presença de Tércio Miranda justamente na região Norte do Brasil onde o anarquismo avançou.

6 PEREIRA, Joana Dias. "Sindicalismo revolucionário em Portugal". Revista Mundos do Trabalho, vol. 1, n. 2, p. 201, 2009.

7 Isso fica evidente com a visita de Elisée Réclus ao Porto em abril de 1886. Ver MESQUITA, Antônio Pedro. "O Pensamento Libertário e Anarquista". In: O pensamento político português no século XX. Uma Síntese Histórico-Crítica. Lisboa: Imprensa Nacional - Casa da Moeda, 2006, p. 523.

8 PEREIRA. "Sindicalismo revolucionário em Portugal", p. 203. 
fortemente estruturadas". ${ }^{9}$ Provavelmente esse contexto estrutural associado às perseguições provocou o deslocamento de Tércio Miranda para o Brasil.

O que se pode aferir, de fato, é que dentre as principais correntes migratórias da Europa para o Brasil, a portuguesa foi a mais significativa numericamente, em especial por ter sido a mais longa e duradoura, estendendo-se do início do século XIX até a metade do século XX. O Brasil não foi o único país de destino, entretanto foi o que mais atraiu os portugueses em grande medida pelo idioma comum, pelos vínculos históricos e pelas "complexas e duradouras relações econômicas e comerciais e uma comunidade local de negociantes dominada por portugueses". ${ }^{10}$

\section{GRÁFICO 1: Total de emigrantes saindo de Portugal e imigrantes portugueses entrando no Brasil (1855-1972)}

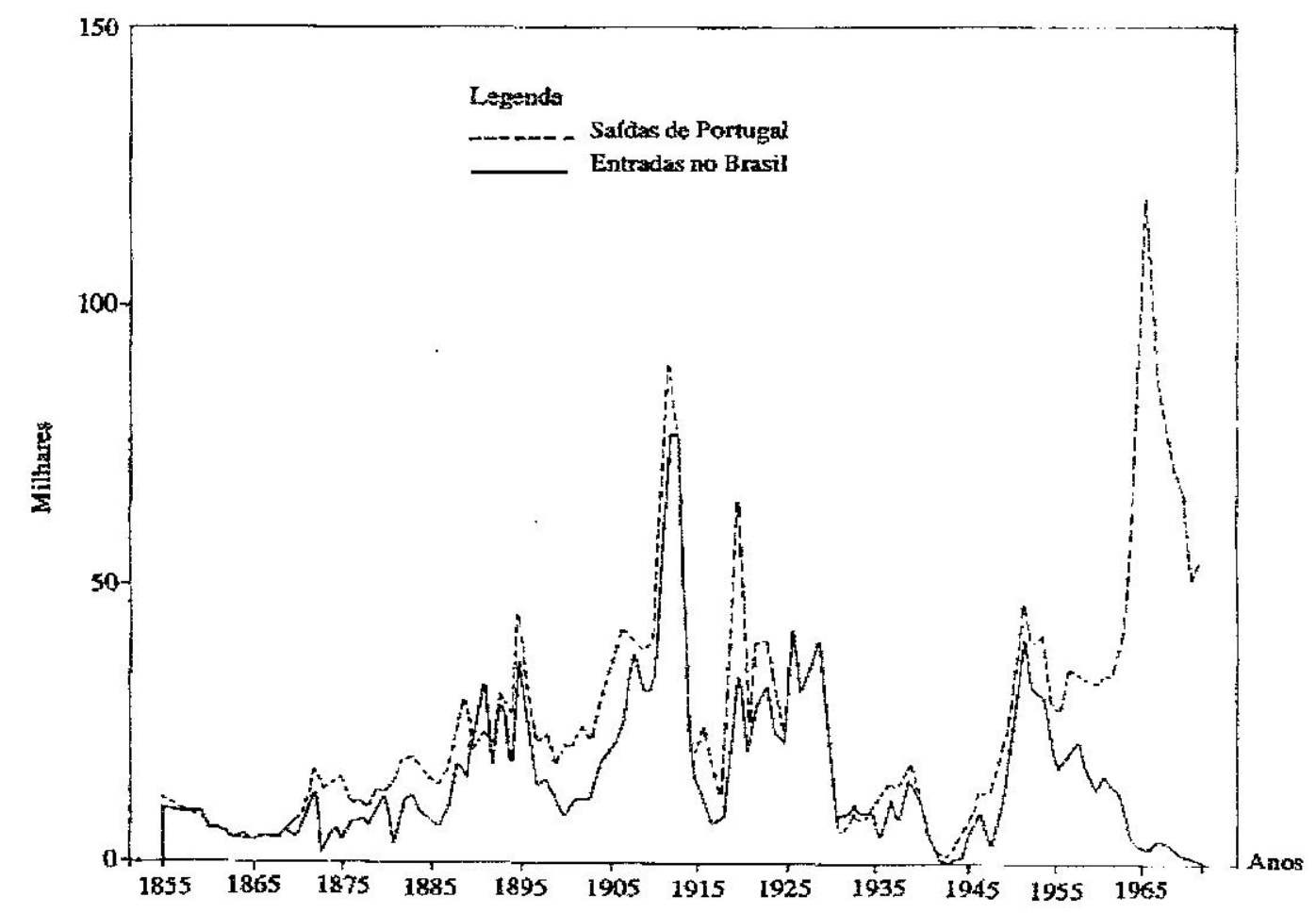

Fonte: KLEIN, Herbert. A integração social e econômica dos imigrantes portugueses no fim do século XIX e século XX. Revista Brasileira de Estudos de População. São Paulo. Vol. 6, n. 2, jul./dez. 1989, p. 18.

Tércio Miranda veio de Portugal para o Brasil por volta de 1912/1913, uma vez que participou do Congresso Operário Brasileiro de 1913. ${ }^{11}$ Portanto, percebe-se que ele realizou esse deslocamento justamente num momento em que a onda migratória para o Brasil atingiu um patamar significativo, como mostra o gráfico acima. Fica evidente também que o Amazonas era um estado que recebia uma quantidade importante de portugueses, conforme a tabela seguinte:

9 KLEIN, Herbert. "A integração social e econômica dos imigrantes portugueses no fim do século XIX e século XX". Revista Brasileira de Estudos de População, São Paulo, vol. 6, n. 2, p. 18, jul./dez. 1989. Ainda segundo o autor, "este movimento de homens (...) foi tão sistemático que o norte de Portugal ficou bastante conhecido, em termos de Europa, pela predominância de mulheres em todas as atividades agrícolas tradicionais".

10 Idem, p. 17.

11 PINHEIRO, Luís Balkar Sá Peixoto. "Imigração, Trabalho e Imprensa em Manaus, 1890-1928". Revista Litteris, n. 14, p. 14, setembro de 2014. 
TABELA 1: Distribuição dos imigrantes portugueses por estado (1920-1970)

\begin{tabular}{|c|c|c|c|c|}
\hline Regiódesístados & 1920 & 1940 & 1950 & 1970 \\
\hline \multicolumn{5}{|l|}{ NORTE } \\
\hline Acre $\ldots \ldots \ldots \ldots$ & 631 & 167 & 99 & 29 \\
\hline Amrazonas ........ & 7.615 & 3.090 & 2.019 & 1.064 \\
\hline Para $\ldots \ldots \ldots \ldots$ & 14.211 & 6,013 & 4.438 & 3,030 \\
\hline Amapa $\ldots . . . \ldots \ldots$ & & - & 41 & 40 \\
\hline Tersit6rio ......... & & & 73 & 50 \\
\hline \multicolumn{5}{|l|}{ NORDESTE } \\
\hline Macanhăo ........ & 625 & 511 & 385 & 240 \\
\hline Piauf .......... . & 66 & 37 & 40 & 29 \\
\hline 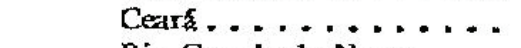 & 296 & 340 & 276 & 200 \\
\hline Rio Grande do Norte . . . . & $8 !$ & 98 & 73 & 52 \\
\hline Paraíba . . . . . . . . . & 131 & 194 & 97 & 78 \\
\hline Pernambuco . . . . . . & 4.809 & 3.048 & 2.308 & 2.402 \\
\hline Alagoas $\ldots \ldots \ldots$ & 237 & 162 & 131 & 139 \\
\hline Sergipe. . . . . . & 125 & 44 & 30 & 44 \\
\hline 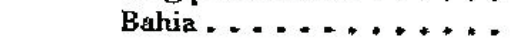 & 3.345 & 1.912 & 1.531 & 1.586 \\
\hline \multicolumn{5}{|l|}{ SUDESTE } \\
\hline Minos Gerais . . . . . . . & 18.228 & 9.310 & 6.472 & 5.156 \\
\hline Espírito Santo . . . . . . . & 1.728 & 1.278 & 789 & 525 \\
\hline Discrito Federa . . . . . & 172.338 & 154.662 & 133.905 & 153.834 \\
\hline Rio de Janeiro . . . . . . & 28.661 & 21.663 & 21.165 & 38.349 \\
\hline Sāo Panlo . . . . . . . . & 167.198 & 165.542 & 151.320 & 214.021 \\
\hline (Cídade de São Faulo) . . . . & $\{64.678\}$ & $(78.949)$ & (n.a.) & $(136.497)$ \\
\hline \multicolumn{5}{|l|}{ SUL } \\
\hline Parană .......... & 1.808 & 3.451 & 4.615 & 9.120 \\
\hline Sants Catarina . . . . . . & 506 & 409 & 318 & 341 \\
\hline Rio Grande do Sul . . . . & 9,324 & 7.167 & 5.667 & 5.189 \\
\hline \multicolumn{5}{|l|}{ CENTRO-OESTE } \\
\hline Mato Grosso ........ & 1.310 & 1.015 & $72 R$ & 956 \\
\hline Goiss . . . . . . . . & 304 & 293 & 317 & 634 \\
\hline Brasdia.......... & & & & 875 \\
\hline TOTAE DE PORTUGUESES . . . & 433.577 & 380.316 & 336.837 & 437.983 \\
\hline TOTAL DE IMIGRANTES . . . . & 1.565 .961 & 1.406 .342 & 1.213 .974 & 1.229 .122 \\
\hline POPULAĞÄO TOTAL . . . . . & 9.930 .478 & $41,165,298$ & 51.941 .767 & 93.139 .037 \\
\hline
\end{tabular}

Fonte: LEVY, 1974, p. 79-82 Apud KLEIN, Herbert. A integração social e econômica dos imigrantes portugueses no fim do século XIX e século XX. Revista Brasileira de Estudos de População. São Paulo. Vol. 6, n. 2, jul./dez. 1989, p. 22.

No Amazonas, a comunidade portuguesa era importante e com a expansão da economia gomífera (1890-1913) ampliou-se ainda mais, com a chegada de novos imigrantes. Consoante Pinheiro, "de longa data os portugueses controlavam boa parte do comércio lojista, de padarias e mercearias". Atuavam também em outros serviços, como portuários e gráficos..$^{12}$ Ainda segundo a autora:

A tomar-se como verdadeira a afirmação do cônsul português em 1916, a "colônia portuguesa em Manaus [possuía] mais de metade da propriedade urbana, que [rendia] anualmente a Portugal cerca de mil contos fortes". Vinte anos antes, outro cronista português, Lourenço da Fonseca, já registrava essa primazia, argumentando que "dos seus 25.000 habitantes, talvez um terço seja de estrangeiros, a maior parte

12 PINHEIRO, Maria Luiza Ugarte. "Portugueses no universo do trabalho manauara (1880-1920)". In: ARRUDA, José Jobson de Andrade, FERLINI, Vera Lucia Amaral, MATOS, Maria Izilda Santos de, SOUSA, Fernando de. (Orgs.). De Colonos a Imigrantes: I(E)migração portuguesa para o Brasil. São Paulo: Alameda, 2013, p. 564. 
filhos de Portugal". Esse fato é posteriormente (1907) corroborado por Hermenegildo de Campos: "Quanto à nacionalidade da população na capital, podemos calcular perto de 10.000 estrangeiros para 50.000 brasileiros. A maior colônia é a dos portugueses, avaliada por competentes em 5.000". ${ }^{13}$

Essa presença também pode ser evidenciada pelos jornais publicados no Amazonas pelos portugueses que aqui estavam radicados: O Lusitano, A Voz de Loriga, O Loriguense, O Poveiro, Alma Portuguesa e outros. Por meio desses jornais, asseguravam um vínculo identitário e procuravam manter-se conectados com suas comunidades de origem na Europa. ${ }^{14}$

Pode ser que Tércio Miranda possuísse contatos no Amazonas, uma vez que a comunidade portuguesa era significativa e estava em conexão permanente com a Península Ibérica, a ponto dele, ao chegar à região, logo se inserir como gráfico em jornais locais, desenvolvendo aí sua atividade profissional.

Sabe-se que quando Tércio Miranda veio para o Brasil já tinha contato com o sindicalismo revolucionário e o anarquismo, muito em função da sua militância no movimento operário português. No Brasil, participou do $2^{\circ}$ Congresso Operário, o que deve ter contribuído significativamente para o seu engajamento em defesa da causa operária em Manaus.

Nesse congresso, as discussões giraram em torno das questões de "cooperativismo, carga horária diária de trabalho, salário mínimo, bolsas de trabalho e, principalmente, do modelo organizativo, afirmando mais uma vez o sindicalismo revolucionário". Além dessas questões, foram destacadas a propaganda, a organização e a educação dos trabalhadores como fundamentais. A imprensa operária foi considerada como um instrumento eficaz de orientação doutrinária e pedagógica. Foi debatido ainda o caráter internacionalista da luta pela emancipação humana, com envio de moções de apoio "aos trabalhadores do México, CGT da França e trabalhadores de Portugal e da Espanha". ${ }^{15}$

Em que pese as divergências políticas e ideológicas presentes no universo dos trabalhadores, cujos reflexos foram marcantes nas discussões travadas no $2^{\circ}$ Congresso, ficou latente a propagação dos ideais libertários aos trabalhadores organizados em torno da C.O.B. (Confederação Operária Brasileira) e do jornal, porta voz da Confederação, A Voz do Trabalhador. ${ }^{16}$

Lideranças de outros estados que participaram do $2^{\circ}$ Congresso Operário Brasileiro devem ter retornado aos seus universos locais convictas da necessidade de lutar pela emancipação operária, não medindo esforços em organizar os trabalhadores em associações, fundar jornais para defender o projeto e buscar uma articulação de caráter internacional. Assim, foi com esse espírito que Tércio Miranda, na qualidade de delegado especial da C.O.B., atuou no Amazonas a partir de $1912 / 1913$.

13 PINHEIRO. "Portugueses no universo do trabalho manauara".

14 PINHEIRO. "Imigração, Trabalho e Imprensa", p. 11.

15 MATEUS, João Gabriel da Fonseca. "O Sindicalismo Revolucionário como estratégia dos Congressos Operários (1906, 1913, 1920)". Enfrentamento, Goiânia, ano 7, n. 12, p. 70-71, ago./dez. 2012.

16 MARQUES, João Carlos. "A Voz do Trabalhador: cultura operária e resistência anarquista no Rio de Janeiro (1908-1915)". (Dissertação de mestrado, Universidade Estadual de Londrina, 2013), p. 51. 


\section{O jornal A Lucta Social (1914)}

Após sua participação na C.O.B., em 1913, Tércio Miranda atuou no Amazonas com o objetivo de organizar os trabalhadores da região. Essa liderança anarquista, afirmando a perspectiva do sindicalismo revolucionário defendida no citado congresso, foi responsável pela difusão desses ideais pelo norte do país, ${ }^{17}$ indo muito além do Amazonas, embora residisse e trabalhasse em Manaus..$^{18}$

Sobre o sindicalismo revolucionário existe uma longa discussão. Toledo o percebeu como uma corrente política autônoma, descolada do socialismo e do anarquismo, em que pese às aproximações com este último, em especial no que tange a ação direta, o antimilitarismo, a greve geral, o anticlericalismo e outros. Para a autora, a característica fundamental que acabou demarcando a fronteira dessa corrente foi a percepção do sindicato como instrumento decisivo de luta, assentado na neutralidade política e religiosa e vislumbrado como a base da futura sociedade. ${ }^{19}$ Nas palavras da autora:

O novo do projeto sindicalista revolucionário era essa tentativa de conciliar a luta para obter vantagens a curto prazo no quadro do sistema existente, com uma perspectiva a longo prazo de derrubar o capitalismo e instaurar um sistema de propriedade coletiva dos meios de produção, geridos pelos próprios trabalhadores através dos sindicatos. Portanto, a função do sindicato era dupla: consistia ao mesmo tempo em melhorar a condição operária e preparar sua emancipação futura, sendo dessa forma luta política e econômica juntas. ${ }^{20}$

Por outro lado, ao contrário de Toledo, Oliveira concebeu o sindicalismo revolucionário como um método de ação atrelado ao anarquismo. ${ }^{21}$ Nesse sentido, um punhado de anarquistas viu no sindicalismo uma forma de ação para lutar contra seus adversários e se fazer presente entre as categorias de trabalhadores. Para o autor tinham que:

manterem-se atuantes no meio operário para conseguir adeptos e combater seus adversários. Um método que, se não exclusivo, foi instrumentalizado a tal ponto de ser apresentado como o método em contraposição aos métodos "maliciosos" de seus adversários, principalmente no que se refere às tentativas de atrelamento das associações sindicais a um partido. ${ }^{22}$

Portanto, como salientou Oliveira, o sindicalismo revolucionário era uma "estratégia, um meio, uma base na qual pudessem semear seus princípios e

17 A Lucta Social, Manaus, $1^{\circ}$ set. 1914, p. 1.

18 Luís Balkar Sá Peixoto Pinheiro, em pesquisa recente, ainda não publicada, vem tentando demonstrar a importância de lideranças operárias no âmbito regional. Inclusive já externou em outros trabalhos sua admiração por Tércio Miranda, afirmando ser este "uma liderança admirável, que percebe bem seu papel de mediador entre mundos distantes, mas mantém a convicção e o desejo do internacionalismo da causa operária". PINHEIRO. "Imigração, Trabalho e Imprensa", p. 4.

19 TOLEDO, Edilene Teresinha. "O Sindicalismo Revolucionário em São Paulo e na Itália: circulação de ideias e experiências na militância sindical transnacional entre 1890 e o Fascismo". (Tese de doutorado em História, UNICAMP, 2002). P. 4-5.

20 TOLEDO. "O Sindicalismo Revolucionário em São Paulo e na Itália", p. 6.

21 OLIVEIRA, Tiago Bernardon de. "Anarquismo, sindicatos e revolução no Brasil (1906-1936)". (Tese de doutorado em História, Universidade Federal Fluminense, 2009). P. 26-27.

22 OLIVEIRA. "Anarquismo, sindicatos e revolução no Brasil", p. 31. 
instigar os trabalhadores e até mesmo os outros sindicalistas (...) às formas de solidariedades que fossem ensaios da solidariedade ácrata futura". ${ }^{23}$

Essas disputas pelo controle do movimento operário também foram destacados por Silva Júnior ao estudar as sociedades de socorros mútuos. Como assinalou o autor, embora no discurso houvesse uma crítica às associações de caráter mutualista, na prática foram tolerados pelos anarquistas com o objetivo de permitir uma maior penetração no universo operário e assim preparar o terreno para a prática revolucionária. Afirmou não existir posição unânime entre os anarquistas, o que contribuiu para as diferentes práticas sindicais ou mutualistas. ${ }^{24}$

Com efeito, entende-se o sindicalismo revolucionário de Tércio Miranda na esteira de Oliveira, ou seja, como um método de ação visando propagar no meio operário os ideais anarquistas, como se pode verificar no trecho a seguir: "O sindicato não é outra coisa que a associação de classe, onde o operário fortifica a sua consciência e estuda as questões que interessam as suas necessidades". ${ }^{25}$ Em outros termos, é um "organismo de combate social, é uma tarefa de lucta de classes; é de resistência e de educação". ${ }^{26}$

Sobre o primeiro número do jornal A Lucta Social, é possível sublinhar a direção imposta ao impresso, ou seja, a quem ele buscava se identificar, se diferenciar e se dirigir:

Não somos eruditos nem Herodotos; não frequentamos Universidades ou Academias para adquirir um papel pelo qual se nos auctorizasse a viver sem trabalhar. Não. Os nossos paes não eram burguezes nem mandões, por isso quem pensar encontrar nestas columnas linitivo ao espírito ocioso que produz o rizo do burguez, engana-se. A nossa escola é outra: Somos operários e a nossa illustração, quer intellectual, quer material, é a menos imperfeita de todas porque é colhida no templo onde as imagens são: martellos, arados, serrotes, plainas, cutellos, enxadas, machados, e, emfim, outros santos mais de que se compõe nossa egreja cujo fim único é a propagação do trabalho, porque sem este era impossível a vida.

Repetimos: a nossa universidade é a forja, o atelier, a húmida mansarda...27

Certamente que Tércio Miranda, como editor do jornal, buscou apresentar o campo operário a partir de dois elementos: trabalho e exclusão. Assim, procurou demarcar o universo operário como aquele cuja vivência e experiência brotavam do espaço de trabalho - "atelier" - e do uso de seus instrumentos - "martelo", "serrote", "arado" -, diferenciando-os do mundo dos burgueses, estes percebidos como "ociosos" e "mandões". Além disso, o elemento da exclusão foi mencionado por meio da educação, do não acesso à universidade.

Nessa esteira, denominando-se como "Orgam Operário-Livre" orientava os trabalhadores a ler o jornal e compartilhá-lo com os camaradas; além de alertar acerca do interesse em estudar as questões sociais necessárias para a interpretação social e a futura emancipação.

23 OLIVEIRA. "Anarquismo, sindicatos e revolução no Brasil", p. 32.

24 SILVA JÚNIOR, Adhemar Lourenço da. "As sociedades de socorros mútuos: estratégias privadas e públicas (estudo centrado no Rio Grande do Sul, 1854-1940)". (Tese de doutorado em História, Pontifícia Universidade Católica do Rio Grande do Sul, 2004). p. 431.

25 A Lucta Social, Manaus (Suplemento ao número 1), 27 fev. 1914, p. 1.

26 A Lucta Social, Manaus, $1^{\circ}$ mai. 1914, p. 4.

27 A Lucta Social, Manaus, 29 mar. 1914, p. 1. 
Tércio Miranda, ao fundar o jornal, estava seguindo aquilo que foi deliberado na C.O.B. Utilizando-o como instrumento de difusão dos ideais libertários, procurou debater as questões que assolavam os trabalhadores, como as muitas horas de trabalho, atraso nos pagamentos, carestia de vida e outros. Colocou-o como espaço de discussão da situação dos trabalhadores no interior da sociedade contemporânea, realizando análises e interpretações acerca da divisão social do trabalho, do governo representativo burguês, do salário, da forma de organização e das ações a serem adotadas no processo de luta contra o capitalismo e para a emancipação humana.

Utilizando a "palavra como arma"28 não poupou esforços em criticar o sistema capitalista de produção, desnudando a exploração que trazia em seu bojo e sugerindo um processo de luta onde os protagonistas da nova situação social um mundo justo, humano e igualitário - fossem os próprios trabalhadores.

Interessante perceber a feitura do jornal A Lucta Social. Toda correspondência relativa ao jornal era enviada a Tércio Miranda (Caixa Postal, 78 - Manaus). Este era, certamente, responsável pela sua editoração e impressão. Nesse processo, tanto a experiência quanto os contatos ainda realizados com seus companheiros de luta em Portugal foram importantes e deixaram suas marcas no jornal.

Nesse sentido, pode-se dizer que o encontro com os ideais libertários foi realizado ainda em solo português. O contato com as obras de Piotr Kropotkine ${ }^{29}$ se deu no interior do "Grupo D'Aurora". Kropotkine era a principal referência anarquista junto ao grupo, ${ }^{30}$ sobretudo do ideal de uma sociedade organizada em bases igualitárias e sem autoridade, o comunismo anarquista. José Prat, ${ }^{31}$ espanhol de grande influência na Europa, difundia em seus escritos, que igualmente circulavam em torno do grupo,,$^{32}$ uma estrutura organizativa do tipo da Confederação Geral do Trabalho Francesa (Sindicatos/Federação), defendendo o sindicalismo revolucionário como ferramenta para a destruição do capitalismo em prol do socialismo, sem negar as conquistas materiais mais imediatas a serem alcançadas por meio das greves parciais que se transformariam em greve geral revolucionária. 33

Emile Pouget ${ }^{34}$ engrossava a defesa do sindicalismo revolucionário, externando suas bases. Além deles, existiam mais duas referências: Clemencia Jacquinet e Elisée Reclus. Aquela pela sua História Universal, utilizada na Escola Moderna de Barcelona de Ferrer a partir de 1901, que oferecia uma "visão detalhada do que os anarquistas, dentro do pensamento pedagógico do racionalismo, entendiam como o ensino de história". Para Jacquinet essa obra tinha uma finalidade:

Compreender de muitas diversas maneiras a história da civilização, desde o surgimento do homem sobre a Terra, nos esforçamos para reconstruir a vida real com todas as suas lutas, sofrimentos e progressos;

28 SCHMIDT, Benito Bisso. "A palavra como arma: uma polêmica na imprensa operária porto-alegrense em 1907". História em Revista, UFPel, v. 6, p. 59-84, dez./2000.

29 Palavras dum Revoltado (2005), A Grande Revolução (1935), A Conquista do Pão (1975), Em Volta de uma Vida (1907), A Anarquia, sua Filosofia, seu Ideal (2000) são algumas de suas obras que provavelmente eram lidas em Portugal, todas traduzidas ao português.

30 CRUZ. "O movimento libertário portuense", p. 17.

31 Com destaque para A Burguesia e o Proletariado (1909) e O Sindicalismo (1909). Ambos publicados em espanhol.

32 CRUZ. "O movimento libertário portuense", p. 19.

33 CRUZ. "O movimento libertário portuense", p. 17-19.

34 São suas as obras: A Confederação Geral do Trabalho (1909) e Bases do Sindicalismo (1906). As duas publicadas em português. 
procuramos colocar a nu a maldade de todos os exploradores: guerreiros, legisladores, sacerdotes e todo o conjunto de ilusões que sofrem o povo, os verdadeiros, os que trabalham; deduzimos um ensino completo e severo para instruir as novas gerações para o conhecimento dos seus verdadeiros direitos e de seus verdadeiros deveres: que seja uma escola de fraternidade universal, um testemunho de paz para o homem honrado e um motivo de terror e espanto para aqueles que tentam subjugar os seus irmãos. ${ }^{35}$

Já Elisée Reclus, ${ }^{36}$ geógrafo e militante libertário, teve uma ligação significativa com o movimento anarquista português, realizando mais de uma visita àquele país na promoção do seu movimento. A segunda viagem desse personagem a Portugal, em 1886, foi marcante, com a reestruturação do movimento sindical em bases libertárias:

Reclus apontava desdobramentos aviltantes, nos quais a vida encontrava-se várias vezes diminuída. As altas taxas de mortalidade, decorrentes de uma lógica econômica perversa, condenavam à morte as populações famintas e privadas das condições básicas de higiene e saúde.

(...)

Assim, milhões de seres humanos eram condenados à fome, às doenças, à mortalidade precoce, ao trabalho exaustivo, ao sacrifício da liberdade de pensamento, à renúncia da felicidade presente em função da promessa de um paraíso futuro... ${ }^{37}$

Para Reclus, "a luta em curso era, sobretudo, uma batalha pela vida no seu sentido mais amplo, com tudo que ela podia conter de afirmativo, como a solidariedade, a felicidade, o acesso ao conhecimento, à liberdade" num mundo mais justo e humano..$^{38} \mathrm{Com}$ efeito, no norte do país, e particularmente no Porto, os anarquistas, incluindo aí Tércio Miranda, sob essas influências, ingressaram nas associações de classe e eram os principais responsáveis pela introdução do sindicalismo revolucionário no movimento operário.

Essas referências que fizeram parte da trajetória anarquista de Tércio Miranda na Europa marcaram presença nas páginas do jornal A Lucta Social. Trazendo os textos consigo ao se deslocar para o Brasil ou recebendo-os via correio ou ainda tendo acesso a determinados trechos em telegramas, esse material adentrou na oficina gráfica. O quadro a seguir explicita a quantidade de artigos e as matérias tratadas:

35 MORAES, José Damiro de. "Leitura que recomendamos - o que todos devem ler: impressos didáticos e ensino de História nas escolas anarquistas". Cadernos de História da Educação, vol. 2, n. 1, p. 55, jan./jun. 2013.

36 Com destaque para: Evolução, revolução ideal anarquista (2002).

37 DUARTE, Regina Horta. "Natureza e sociedade, evolução e revolução: a geografia libertária de Elisée Reclus". Revista Brasileira de História, São Paulo, vol. 6, n. 51, p. 16-17, 2006.

38 DUARTE. "Natureza e sociedade, evolução e revolução", p. 18. 
Quadro 1

\begin{tabular}{llll}
\hline Autores & Procedência & Título da matéria & $\begin{array}{l}\text { Data da publicação } \\
\text { no A Lucta Social }\end{array}$ \\
\hline José Prat & $\begin{array}{l}\text { Conferência no Centro da } \\
\text { Juventude Republicana } \\
\text { de Lérida - Espanha }\end{array}$ & Aurora Proletária & $\begin{array}{l}\text { Ano I, n. 1, 29 de } \\
\text { março de 1914 }\end{array}$ \\
\hline Piotr Kropotkine & --- & O Salariato & $\begin{array}{l}\text { Ano I, n. 1, 29 de } \\
\text { março de 1914 }\end{array}$ \\
\hline Emile Pouget & --- & Os Sindicatos & $\begin{array}{l}\text { Ano I, n. 2, } 1^{\circ} \text { de maio } \\
\text { de 1914 }\end{array}$ \\
\hline Montesquieu & Espírito das Leis & Operários & $\begin{array}{l}\text { Ano I, n. 3, } 1^{\circ} \text { de junho } \\
\text { de 1914 }\end{array}$ \\
\hline Salvaterra Júnior & --- & Ferrer... História & $\begin{array}{l}\text { Ano I, n. 3, } 1^{\circ} \text { de junho } \\
\text { de 1914 }\end{array}$ \\
\hline Emile Pouget & --- & Simples & $\begin{array}{l}\text { Ano I, n. 3, } 1^{\circ} \text { de junho } \\
\text { de 1914 }\end{array}$ \\
\hline Clemencia Jacquinet & História Universal & A Greve & $\begin{array}{l}\text { Ano I, n. } 4,1^{\circ} \text { de } \\
\text { setembro de 1914 }\end{array}$ \\
\hline Elisée Reclus & --- & O Ideal Futuro & $\begin{array}{l}\text { Ano I, n. } 6,1^{\circ} \text { de } \\
\text { novembro de 1914 }\end{array}$ \\
\hline
\end{tabular}

Fonte: A Lucta Social - quadro construído pelo próprio autor.

Acredita-se que outros expoentes do anarquismo eram, da mesma forma, lidos, como Neno Vasco, Alfred Naquet, Enrico Malatesta, Bakunin e demais cujos textos não foram oportunizados no conjunto dos jornais preservados (particularmente os seis números trabalhados aqui), mas talvez em outros números que não tiveram o mesmo destino.

O jornal ainda fez menção a Montesquieu, em especial a trecho do Espírito das Leis. ${ }^{39}$ É possível observar que Tércio Miranda, assim como os portugueses que residiam no Amazonas, manteve contato com pessoas em Portugal, companheiros de luta. Salvaterra Júnior pode ser um exemplo. Arrisca-se a imaginar que este era amigo de Tércio Miranda, uma vez que também era membro do "Grupo Aurora Social", liderando organizações libertárias no Porto como, por exemplo, "A Libertadora", "O Centro de Instrução Livre", "O Germinal/Centro Instrutivo" e outros..$^{40} \mathrm{Com}$ uma ampla participação, Salvaterra Júnior atuava de forma ativa no movimento, inclusive produzindo textos, particularmente poemas que ganharam as páginas do A Lucta Social. Por exemplo:

I

Ele é como Jesus bom para as criancinhas

A quem dedica amôr e mimo fraternal:

Confiando o Porvir, o seu sonho ideal,

Ao magote infantil daquelas andorinhas!...

Não que as creanças são como essas avesinhas

Que com muito saber e geito maternal,

É preciso ensinar a esvoaçar sosinhas,

Do brando e quente ninho, à Vida Racional!...

39 A Lucta Social, Manaus, 1 jun. 1914, p. 3.

40 CRUZ. "O movimento libertário portuense", p. 22-26. 
Ele mostra sorrindo o Dever e a Nobreza, E a par da intensa luz clara da ciência [explorar]

Esfolha aos seus olhar's, num livro - a Natureza.

E como é um eróe nas lutas de consciência, Os biltres do poder, padres e realezas, Na fúria do chacal, matam-no sem clemencia!...

II

Satánica aliança, ó bando tenebroso! - Reis e militares, padres e burguesia, Scutai a minha voz, cheia de rebeldia, Num rugido de raiva, audaz, desrespeitoso:

Eu sou como Ferrer um grande criminoso, Pois ando a estudar um dia e outro dia, A fórma de acabar com a supremacia Desse vosso poder, antigo, monstruoso!...

Eu escarneço as leis e odeio as catedrais; E um dia hei-de fazer co'o fogo do meu peito Ateado pelo amor dos modernos ideais,

Um facho a crepitar... num incêndio desfeito, Os cétros, as prizões, fardas e tribunais, Hei-de tornar em pó, em nome do Direito!... ${ }^{41}$

Este poema é bastante representativo e elucidativo por apontar questões ligadas ao anarquismo. A primeira delas se refere à ciência. Para os adeptos dessa corrente, a realidade social tinha que ser percebida e analisada racionalmente, de forma científica. Não foi algo exclusivo apenas dos anarquistas. Conforme Schmidt:

Em um contexto em que a crença no progresso e nos poderes ilimitados da ciência era hegemônica, muitos militantes, das mais diversas correntes ideológicas, procuraram interpretar a realidade local e justificar suas concepções políticas a partir de "critérios científicos".42

A segunda questão aponta para uma divisão social assentada numa hierarquia. Para os anarquistas, por meio dela, um punhado de pessoas adquiria poder político e econômico, utilizando-o para promover acumulação de riquezas e desigualdades sociais. Para isso, lançavam mão de explorações diversas, colocando-se como inimigos sociais. Reis, padres, militares e burguesia reproduziam, justificavam, mantinham e/ou reforçavam, com suas práticas e comportamentos, o quadro de exploração e injustiças. Nesse sentido, para viabilizar a justiça social era necessário acabar com a supremacia desses grupos, "os biltres do poder", assim como suas instituições, "cétros, prizões, fardas e tribunais".

Com efeito, a ligação de Tércio Miranda com os companheiros de luta do Porto continuava, o que demonstrou a natureza do vínculo estabelecido, como também as interações e conteúdos que circulavam a partir dessa "rede de relações"43 constituída

41 A Lucta Social, Manaus, $1^{\circ}$ jun. 1914, p. 5.

42 SCHMIDT, Benito Bisso. "O Deus do progresso: a difusão do cientificismo no movimento operário gaúcho da I República". Revista Brasileira de História. São Paulo, vol. 21, n. 41, p. 114, 2001.

43 Deixando de lado as discussões acerca de outras perspectivas, entende-se por redes de relações o estabelecimento de vínculos e interações por onde corriam informações, modelos interpretativos e organizacionais direcionados aos trabalhadores dentro de uma perspectiva de metodologia de redes 
no processo de luta libertária. E essa rede não se restringia ao Porto. Tais vínculos, contatos e interações ocorriam com militantes que circulavam e atuavam na Europa, mas também em outras regiões do Brasil, como é possível demonstrar abaixo:

Quadro 2

\begin{tabular}{|c|c|c|c|}
\hline Cidade/Estado & Procedência & Título da matéria & $\begin{array}{l}\text { Data da publicação no } \\
\text { A Lucta Social }\end{array}$ \\
\hline Belém/Pará & $\begin{array}{l}\text { Reunião d'Assembléa } \\
\text { Geral }\end{array}$ & Moção & $\begin{array}{l}\text { Suplemento ao } \\
\text { número 1, } 27 \text { de } \\
\text { fevereiro de } 1914\end{array}$ \\
\hline Belém/Pará & $\begin{array}{l}\text { Secretaria da "União dos } \\
\text { Operários Sapateiros do } \\
\text { Pará" }\end{array}$ & $\begin{array}{l}\text { A "conducta" de } \\
\text { Demoniz }\end{array}$ & $\begin{array}{l}\text { Ano I, n. } 2,1^{\circ} \text { de maio } \\
\text { de } 1914\end{array}$ \\
\hline Belém/Pará & -- & $\begin{array}{l}\text { NO PARÁ: Um governo } \\
\text { despótico - Gréve } \\
\text { motivada pela fome - } \\
\text { Prizões - Deportações } \\
\text { de operários - Assalto às } \\
\text { sociedades - Outras notas }\end{array}$ & $\begin{array}{l}\text { Ano I, n. } 3,1^{\circ} \text { de junho } \\
\text { de } 1914\end{array}$ \\
\hline Ceará/Fortaleza & $\begin{array}{l}\text { Órgão Operário de } \\
\text { Fortaleza }\end{array}$ & Em face dos contrastes & $\begin{array}{l}\text { Ano I, n. } 3,1^{\circ} \text { de junho } \\
\text { de } 1914\end{array}$ \\
\hline Belém/Pará & --- & $\begin{array}{l}\text { A greve em Belém do } \\
\text { Pará }\end{array}$ & $\begin{array}{l}\text { Ano I, n. } 3,1^{\circ} \text { de junho } \\
\text { de } 1914\end{array}$ \\
\hline Belém/Pará & -- & $\begin{array}{l}\text { A "conducta" de } \\
\text { Demoniz }\end{array}$ & $\begin{array}{l}\text { Ano I, n. } 3,1^{\circ} \text { de junho } \\
\text { de } 1914\end{array}$ \\
\hline
\end{tabular}

Fonte: A Lucta Social - quadro construído pelo próprio autor.

Todas essas matérias pararam nas mãos de Tércio Miranda e, de alguma forma, ganharam as páginas do jornal. Cabe destacar que elas compunham algo em torno de $60 \%$ do que foi publicado nos seis números trabalhados. ${ }^{44}$

Além delas, e como não podia deixar de ser, as questões locais do movimento libertário, a organização dos trabalhadores, as disputas internas, os problemas que assolavam a classe eram retratados dentro de uma leitura de luta e de embate entre projetos de sociedades diferentes, como ficou evidente no trecho abaixo:

Assim, pois, camaradas, é chegada a hora de ajustar contas com elles, nós que tudo produzimos e nada possuímos (...) é necessário, é indispensável pois, que todos os que vivemos do trabalho pensemos ao menos CINCO MINUTOS no nosso futuro e no de nossas famílias.

Associa-te, organiza-te em associações onde encontrarás o antídoto poderoso que, ajudar-te-á a levar a cabo a grande obra da regeneração humana, mostrando assim que sabes comprehender os laços de solidariedade que atravéz das fronteiras se cruzam uníssonos, em holocausto da tua emancipação integral. 45

sociais na qual o foco recai nesse processo. Ver IMízCOZ, José Maria. "Actores, redes, processos: reflexiones para una história más global". Revista da Faculdade de Letras/História, Porto, Série III, vol. 5, p. 115-140, 2004. Para um debate sobre a emergência dessa metodologia e suas perspectivas ver: PORTUGAL, Sílvia. Contributos para uma discussão do conceito de rede para a Teoria Sociológica. Oficina do CES, p. 1-35, mar./2007.

44 Sobre essa questão, e considerando os jornais operários que circularam no Rio Grande do Sul, ver PETERSEN, Sílvia Regina Ferraz. Guia para o estudo da imprensa periódica dos trabalhadores do Rio Grande do Sul (1874-1940). Porto Alegre: UFRGS/FAPERGS, 1989.

45 A Lucta Social, Manaus, $1^{\circ}$ mar. 1914, p. 2. 
Dessa forma, ficou evidente um projeto de organização dos trabalhadores em associações. Estas eram vistas como fundamentais para a melhoria das condições de vida e trabalho e, consequentemente, importantes para as gerações futuras. Nessa esteira, a reflexão sobre a situação social da categoria e o entendimento dos laços de solidariedade como instrumentos de coesão se colocavam como essenciais para a construção de uma estrutura organizativa, de dimensões internacionais, que promovesse a igualdade e a justiça social, rompendo com a distribuição desigual da riqueza e da acumulação capitalista.

Todas essas matérias, internacionais, nacionais e locais, foram distribuídas por Tércio Miranda no jornal, que tinha o formato de $22 \times 30 \mathrm{~cm}$, em geral com quatro páginas e três colunas. O número de páginas variava conforme problemas de ordem material ${ }^{46}$ ou em função de comemorações relacionadas ao universo do trabalhador. ${ }^{47}$

\section{Imagem 1}
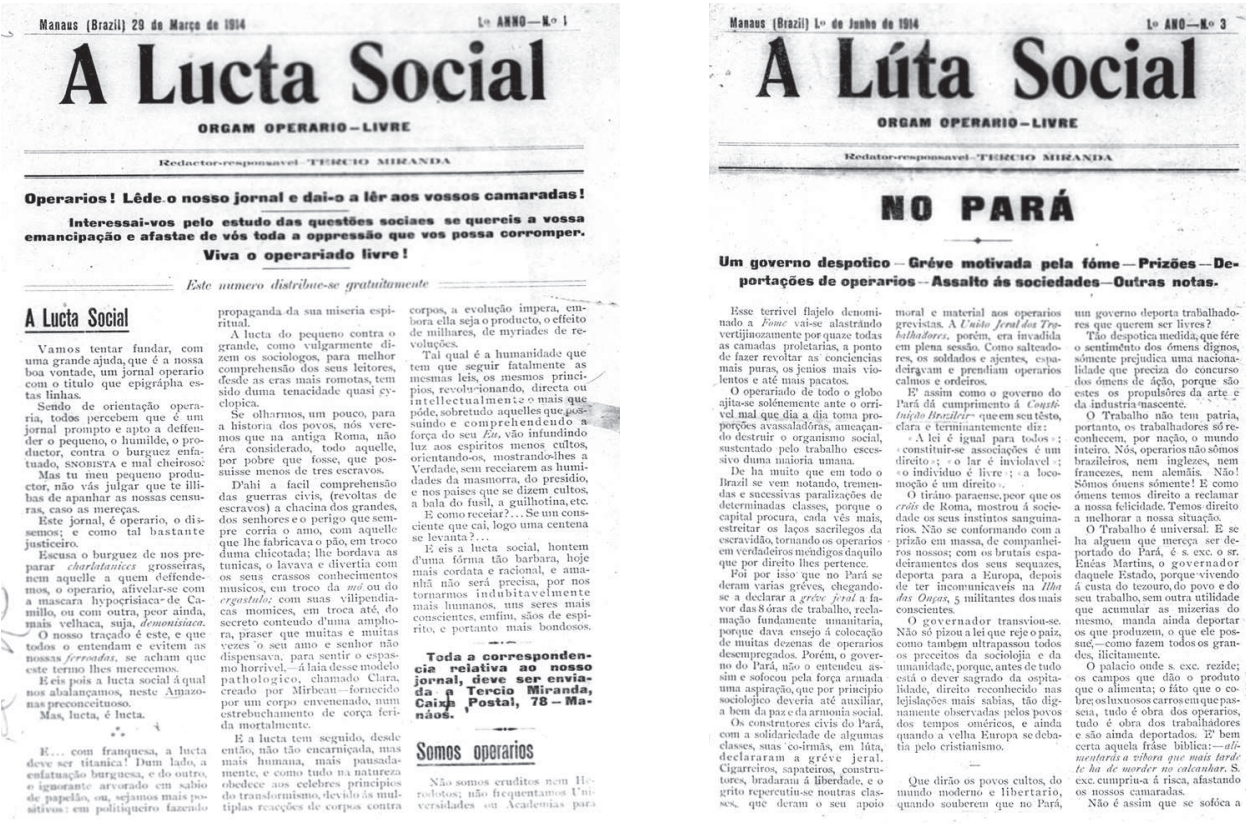

Fonte: PINHEIRO, Maria Luiza Ugarte, PINHEIRO, Luís Balkar Sá Peixoto (orgs). Imprensa Operária no Amazonas - Transcrições e Fac-símiles (Documentos da Amazônia, vol. 1). Manaus: EDUA, 2004, p. 75 e 91.

Para se compreender a imprensa operária não se pode negligenciar os contatos, os vínculos e as interações que o grupo produtor do jornal efetuou com outros militantes localizados em outras regiões, resultando daí a necessidade de identificar os membros do grupo, as suas interações e influências. Isso leva a outras questões como "dar conta das motivações que levaram à decisão de dar publicidade a alguma coisa", atentando para "o destaque conferido ao acontecimento" e o local, na distribuição das notícias, onde se deu a publicação. ${ }^{48}$

46 Em especial, problemas financeiros que impossibilitavam uma impressão maior de folhas e jornais, mas também relacionados ao seu responsável direto, Tércio Miranda, que possivelmente concentrava as diferentes fases de produção do jornal (redação, editoração, impressão, etc.), fazendo com que sua saída dependesse exclusivamente dele. Há relatos que o jornal atrasou algumas vezes pelo fato dele ter adoecido. Ver A Lucta Social, Manaus, $1^{\circ}$ nov. 1914 , p. 1.

47 Como por exemplo, algumas conquistas imediatas (aumento de salário, etc.), aniversário da associação ou comemorações relativas ao $1^{\circ}$ de Maio.

48 LUCA, Tania Regina de. História dos, nos e por meio dos periódicos. In: PINSKY, Carla Bassanezi. (Org.). Fontes Históricas. 2. ed. São Paulo: Contexto, 2006, p. 131-141. 
Nesse processo, a trajetória de Tércio Miranda remeteu para o interior da redação e oficina gráfica do jornal A Lucta Social, o que permitiu ver esses espaços como aglutinadores de textos que vinham de diferentes regiões do país e do mundo, "compondo redes" que conferiram sua formação, estruturação e dinâmica.

\section{Tércio Miranda e o vento anarquista na Amazônia}

De Portugal, mais especificamente da cidade do Porto, para Manaus, capital do Amazonas. Em 1914, já então na Amazônia, fundou um jornal com uma forte influência do sindicalismo revolucionário. Tércio Miranda era então um imigrante que se inseriu no mercado de trabalho como gráfico no decorrer de um processo de transformação urbana oriundo da inserção da região no mercado mundial, via exportação da borracha. Indústrias de produtos de borracha, europeias e norte-americanas, passaram a exigir uma demanda significativa do produto que a Amazônia passou a ofertar. ${ }^{49}$

Importante assinalar que isso fez parte de um processo maior ligado ao sistema capitalista de produção que a partir do século XIX assumiu uma nova fase de expansão, o que ensejou a incorporação de "regiões remotas" do globo, tornandoas palcos da reprodução de capitais. Sobre esse ponto, Eric Hobsbawm destacou:

O fato maior do século XIX é a criação de uma economia global única, que atinge progressivamente as mais remotas paragens do mundo, uma rede cada vez mais densa de transações econômicas, comunicações e movimento de bens, dinheiro e pessoas ligando países desenvolvidos entre si ao mundo não desenvolvido. ${ }^{50}$

No âmbito global, foi esse movimento que levou a Amazônia a ser incorporada ao mercado mundial. Tal fato impactou a cidade de Manaus ${ }^{51}$ que passou a assumir a função de centro comercial. Diversas atividades, em grande medida moldadas pela posição econômica assumida pela cidade, foram desenvolvidas no interior do espaço urbano. Além das firmas estrangeiras que passaram a atuar na administração dos serviços (porto, transporte, energia, abastecimento de água, etc.) ocorreu uma ampliação significativa da praça comercial. Diversos estabelecimentos passaram a comercializar uma variedade de produtos nacionais e importados, assim como uma gama variada de serviços (hotéis, restaurantes, botequins, etc.) passou a ser oferecida.

Além disso, a cidade passou a presenciar o surgimento de marcenarias, sapatarias, alfaiatarias, fábricas de tecido, fábricas de roupas, fábricas de cestas e vassouras, funilarias, tabacarias, fábricas de panificação, fábrica de cerveja e gelo, fábrica de sabão e outros..$^{2}$

Enfim, percebe-se que as atividades econômicas que se desenvolveram no espaço urbano de Manaus tinham como alicerces as atividades de circulação e

49 SANTOS, Roberto. História econômica da Amazônia (1800-1920). São Paulo: T.A. Queiroz, 1980.

50 HOBSBAWM, Eric. A Era dos Impérios. Rio de Janeiro: Paz e Terra, 1988, p. 95.

51 Para Belém, ver: SARGES, Maria de Nazaré. Belém: riquezas produzindo a Belle-Époque (1870-1912). Belém: Paka-Tatu, 2000, FONTES, Edilza (org.) Contando a História do Pará. Da conquista à sociedade da borracha. Vol. I. Belém: E. Motion, 2002.

52 COSTA, Francisca Deusa Sena da. Quando Viver Ameaça a Ordem Urbana: cotidiano de trabalhadores em Manaus, 1915-1925. (Dissertação de mestrado em História, Pontifícia Universidade Católica de São Paulo, 2000). P. 53. 
consumo, havendo a atuação, em pequena escala, de oficinas/fábricas específicas. A ampliação do mercado de trabalho manauara se deu ancorado nessas bases. Não se pode deixar de mencionar também o governo estadual, em especial o serviço burocrático, que exigia também "um corpo técnico para áreas especializadas como saúde, educação, saneamento, etc.", inserindo-se aí "médicos, enfermeiras, juízes, professores, engenheiros" e outros. ${ }^{33}$

Cabe lembrar que a imigração foi essencial para a ampliação das atividades acima destacadas. A partir do final do século XIX, a cidade passou a recepcionar uma onda imigratória crescente. Um número significativo de pessoas (estrangeiros e nacionais), entre elas Tércio Miranda, acabou por marcar presença no universo urbano e a disputar espaços de trabalho nas mais diferentes atividades, como foi mencionado anteriormente. Esse processo se intensificou ainda mais a partir do aumento das exportações da goma elástica e teve reflexos no mundo do trabalho.

A Sociedade União Operária do Amazonas, que surgiu no final da década de 1910 e início de 1920, colocou-se como fundamental. Aglutinou, sob sua responsabilidade, diversos associados, entre nacionais e estrangeiros. Pelo seu livro de registros foi possível identificá-los quantitativamente:

\section{Quadro 3: Nacionalidade dos associados da Sociedade União Operária do} Amazonas (1926)

\begin{tabular}{lc}
\hline Nacionalidade & -- \\
\hline Brasileiros & 895 \\
\hline Estrangeiros & 115 \\
\hline Portugueses & 80 \\
\hline Peruanos & 9 \\
\hline Italianos & 8 \\
\hline Espanhóis & 7 \\
\hline Ingleses & 4 \\
\hline Alemães & 3 \\
\hline Austríacos & 1 \\
\hline Franceses & 1 \\
\hline Russos & 1 \\
\hline Sírio-Libaneses & 1 \\
\hline TOTAL & 1.010 \\
\hline
\end{tabular}

Fonte: Livro de registros da Associação União Operária Amazonense. Acervo Centro de Memória da Justiça do Trabalho da $11^{\circ}$ Região do Amazonas. Apud PINHEIRO, Luís Balkar Sá Peixoto. Imigração, Trabalho e Imprensa em Manaus, 1890-1928. Revista Litteris, n. 14, set./2014, p. 8-9.

Embora as informações contidas na tabela acima se refiram ao ano de 1926, quando a crise da borracha já havia demonstrado sinais de força, gerando falências e desempregos, ${ }^{54}$ elas revelam que os portugueses eram a maioria entre os estrangeiros na associação, número que deveria ser muito maior na década

53 PINHEIRO, Maria Luiza Ugarte Pinheiro. Nos meandros da cidade: cotidiano e trabalho na Manaus da borrcha, 1880-1920. Anais do XXIV Simpósio Nacional de História/ANPUH, São Leopoldo/RS, 2007 , p. 5.

54 WEINSTEIN, Bárbara. A Borracha na Amazônia: expansão e decadência (1850-1920). São Paulo: Hucitec, 1993. 
de 1910, em especial no ano que Tércio Miranda se deslocou para o Amazonas, momento em que a crise se anunciava.

Chamou atenção também a quantidade de brasileiros frente a dos estrangeiros, sobretudo nas duas primeiras décadas do século XX onde a preferência pela mão de obra estrangeira se tornou hegemônica em diversas regiões do Brasil, como também no Amazonas. Avelino, estudando o patronato amazonense, assinalou isso:

As discussões da elite patronal na época norteavam o debate em torno da busca, obtenção, de uma espécie de trabalhador tido como ideal. Este tipo de trabalhador, além das qualidades técnicas necessárias e a sua melhor adequação as normas disciplinares, era tido também primordial para o melhoramento da raça local vista por muitos patrões como inferior.

$$
\text { (...) }
$$

A fala do patronato foi marcada pela ideia eugênica de aperfeiçoamento da força de trabalho na Amazônia através da importação de trabalhadores estrangeiros, preferencialmente europeus, que melhor possibilitassem alcançar as metas de produção e comercialização idealizadas pela ACA...55

Não obstante, esse quantitativo nacional certamente foi resultado da aprovação, no âmbito municipal (Lei n. ${ }^{\circ} 979$, de 25 de outubro de 1918) e estadual (Lei n. ${ }^{\circ}$ 962 , de 4 de setembro de 1918), da Lei dos $2 / 3^{56}$ que, embora tenha surgido focada no serviço público feito administrativamente ou por arrendamento, seguramente gerou pressão e resultados em outros espaços.

No Amazonas, como delegado especial da C.O.B., Tércio Miranda procurou desenvolver ações no sentido de organizar os trabalhadores. Utilizou as páginas do jornal que colocou em circulação para falar da importância da solidariedade como peça importante no processo de associação e luta:

Todos se devem lembrar, pois não é muito o tempo passado, que desde a fundação do sindicato, quando eu [Tércio Miranda] me fazia ouvir, mostrava a necessidade de uma áção consciente, para a emancipação, mas nunca me esquecia de dizer, que o nosso primeiro trabalho, devia ser o levantamento moral da classe. Precisávamos da adesão de toda a classe, que não é grande afinal, para estreitarmos indestrutivelmente, os laços da solidariedade, indispensável a nossa vitória. ${ }^{57}$

Ao se empenhar no processo organizativo de diversas categorias de trabalhadores, ${ }^{58}$ principalmente à que pertenciam os gráficos, Tércio Miranda se esforçou para fundar o Sindicato dos Trabalhadores Gráficos em 1914.

Entretanto, cabe apontar que essa não foi a primeira tentativa de organização da categoria, que procurou se movimentar, nesse sentido, desde os anos de 1890 e 1891. Portanto, a fundação do sindicato por Tércio Miranda demonstra uma insistente prática de organização dos trabalhadores gráficos no Amazonas, seguindo o que acontecia nas principais capitais do país.

55 AVELINO, Alexandre Nogueira. "O patronato amazonense e o mundo do trabalho: a revista da Associação Comercial e as representações acerca do trabalho no Amazonas (1908-1919)". (Dissertação de mestrado em História, Universidade Federal do Amazonas, 2008), p. 83-84.

56 Leis que reservavam dois terços das vagas para os trabalhadores nacionais.

57 A Lucta Social, Manaus, $1^{\circ}$ nov. 1914, p. 1.

58 Entre elas, os padeiros e alfaiates (respectivamente o Sindicato dos Operários Manipuladores de Pão e União dos Alfaiates). A Lucta Social, Manaus, $1^{\circ}$ set. 1914, p. 4. 
Com um estatuto ${ }^{59}$ e uma comissão administrativa provisória composta por Tércio Miranda, Domingos Batista Guedes, Joaquim Azpilicueta, Antônio Dias Martins e Ananias Linhares da Silva, o sindicato passou a atuar na defesa dos interesses dos gráficos.

Para Tércio Miranda, as associações deveriam se materializar em sindicatos de resistência e, pela ação direta, buscar ganhos materiais e a promoção da emancipação dos trabalhadores. Ele condenava, de forma categórica, as associações beneficentes, chamando-as de "caça-níqueis" e vendo-as como um obstáculo ao que considerava a "verdadeira" luta social:

A classe está convencida de que a beneficência não traz benefício algum. A prova é que abandonaram o seu organismo, ainda ezistente, com tal fim. Convencidos todavia, que o simples organismo de resistencia era o unico que Ihe convinha, fôi ingressando no seu respétivo Sindicato, alimentando novas esperanças. ${ }^{60}$

Também negava a luta operária pelo viés da representatividade no Parlamento, criticando as alianças eleitoreiras e a colaboração de classes que outras lideranças presentes no cenário urbano de Manaus defendiam. ${ }^{61}$

Com efeito, certamente pelas suas ações, Tércio Miranda incomodou setores da elite local. Diretores e donos de oficinas gráficas ficaram bastante insatisfeitos com os artigos produzidos no jornal que criticavam a ausência de pagamento de salários dos gráficos dos jornais diários Em Tempo e Amazonas, além de, nos mesmos artigos, incentivar esses trabalhadores a cruzarem os braços. Da mesma forma, donos de alfaiatarias, de padarias e outros viam com desconfiança a organização dos seus trabalhadores em associações que Tércio Miranda ajudou a fundar. ${ }^{62}$

Certamente as autoridades públicas, que em geral viam os trabalhadores como "classes perigosas", observaram os artigos no jornal onde Tércio Miranda denunciava a falta de pagamento. Por tudo isso, acredita-se que esse personagem foi uma liderança, uma vez que fundou e escreveu em jornal, atuou no sentido de organizar diversas categorias de trabalhadores e, como delegado especial da C.O.B., circulou para além das fronteiras do Amazonas, desenvolvendo seu raio de ação na Região Norte. Tércio Miranda efetivamente fazia parte de uma minoria de militantes ativos presentes no mundo do trabalho. Sobre a militância operária, asseverou Batalha: "Apenas uma minoria de militantes chega a escrever nos jornais operários e tem uma atuação que transcende os limites de sua categoria profissional; esses podem ser considerados como lideranças operárias". ${ }^{63}$

Nesse sentido, nosso personagem foi uma liderança que atuou e incomodou muita "gente boa" no Amazonas da década de 1910.

59 O Estatuto do Sindicato dos Trabalhadores Gráficos foi publicado no jornal A Lucta Social, Manaus, $1^{\circ}$ set. 1914, p. 6-8.

60 A Lucta Social, Manaus, $1^{\circ}$ nov. 1914, p. 1.

61 Isso foi possível perceber também por outros jornais operários, de cunho reformista, como o Vida Operária e O Extremo Norte, ambos de 1920.

62 A Lucta Social, Manaus, $1^{\circ}$ set. 1914, p. 4.

63 BATALHA, Cláudio Henrique de Moraes. "Vida Associativa: por uma nova abordagem da história institucional nos estudos do movimento operário". Anos 90, Porto Alegre, n. 8, p. 93, dez./1997. 


\section{Considerações finais}

Pela análise da trajetória de Tércio Miranda, aspectos de uma história mais geral puderam ser observados. Em primeiro lugar, revelou-se um significativo processo imigratório de estrangeiros para o Amazonas, em especial portugueses. Associada a esse deslocamento, criou-se uma rede de comunicação, com ligações e interações, nacionais e internacionais, por onde circulavam conteúdos ligados ao mundo operário.

Essa rede foi fundamental para uma ativa atuação de Tércio como liderança operária. Tornou-se delegado especial da C.O.B. e, na esteira das deliberações do $2^{\circ}$ Congresso Operário Brasileiro, ocorrido na cidade do Rio de Janeiro em 1913, realizou diversas atividades no sentido de organizar os trabalhadores, fundando associações e até mesmo um jornal para defender e propagar os ideais anarquistas.

Suas ações externaram as suas influências teóricas, as quais buscou difundir nas páginas do A Lucta Social. Também revelaram as propostas de ações defendidas como o antimilitarismo, o anticlericalismo, a ação direta, a greve geral revolucionária e o sindicato como instrumento de luta econômica-social, o que acabou por revelar não somente as divergências no interior do anarquismo como também em relação ao reformismo.

O percurso do nosso personagem ainda fez emergir algumas mudanças que a capital do Amazonas sofreu após sua inserção no mercado mundial como região exportadora de borracha, como, por exemplo, a ampliação do mercado de trabalho e a presença de trabalhadores que disputavam aí uma colocação. Também jogou luzes em elementos da relação patrão/operário no início do século XX, sobretudo a política de recrutamento de mão de obra estrangeira levada a cabo pelo patronato amazonense seguindo uma tendência nacional, mas que, em grande medida, foi interrompida pela Lei dos $2 / 3$.

Por fim, Tércio Miranda foi um militante que introduziu o anarquismo na região, elencando Manaus como centro de irradiação dessa corrente política por todo o norte do Brasil, constituindo-se, dessa forma, como uma significativa liderança anarquista na Amazônia.

Enviado: 20/06/2016 Aprovado: 06/04/2017 
